\title{
CONTRIBUIÇÃO DA ENFERMAGEM AO COMBATE DA ESQUISTOSSOMOSE EM HOSPITAIS *
}

\author{
Maria Alice de Almeida Ramos** \\ Maria Augusta Ponties** \\ Marta Adélia Baptista** \\ Sandra Regina Patrício** \\ Zilda Halter **
}

RAMOS, M. A. de A.; PONTIES, M. A.; BAPTISTA, M. A.; PATRíCIO, S. R.; HALTER, Z. Contribuição da enfermagem ao combate da esquistossomose em hospitais. Rev. Esc. Enf. USP, São Paulo, 13(2): 189-196, 1979.

As autoras, estudantes de enfermagem, relatam sua experiência no trabalho de campo da disciplina Administração A plicada à Enfermagem. Elaboraram e executaram um plano assistencial para detecção precoce da esquistossomose em familiares de pacientes com esta doença.

No decorrer do estágio de Administração Aplicada à Enfermagem, realizada na 3. ${ }^{a}$ Clínica Cirúrgica do Hospital das Clínicas da Faculdade de Medicina da Universidade de São Paulo, tivemos oportunidade de planejar e administrar cuidados de enfermagem aos pacientes internados nessa unidade. Observamos, então, que os pacientes do "grupo de fígado" eram, em sua grande maioria, esquistossomóticos que se encontravam num estágio bastante avançado da doença.

Segundo MOLINA ${ }^{12}$ e PESSOA $^{14}$, esquistossomose é uma doença crônica e endêmica produzida no homem por infeç̧ão pelo verme do Gênero Schistosoma, sendo os órgãos e tecidos mais freqüentemente afetados: cólon, fígado, baço, bexiga, reto, pulmões, genitália, mesentério e peritônio.

$\mathrm{Na}$ fase da doença em que nossos pacientes se encontravam, todos apresentavam a síndrome de hipertensão portal e, portanto, requeriam tratamento cirúrgico. Para OKUMURA ${ }^{13}$, hipertensão portal é uma síndrome caracterizada pelo aumento da pressão no sistema porta, em conseqüência a um obstáculo intra ou extrahepático ao seu fluxo sangüíneo.

Constatamos que esses pacientes eram, na quase totalidade, migrantes de regiōes onde a esquistossomose é endêmica como: Ceará, Rio Grande do Norte, Paraíba, Pernambuco, Alagoas, Sergipe, Bahia e Minas Gerais, e residentes em São Paulo há algum tempo. AMATO NETO et alii. ${ }^{3}$ e KOROLKOVAS ${ }^{11}$, citam em seus estudos, como áreas endêmicas, as acima relacionadas.

No Estado de São Paulo, em 1923, foram descritos os primeiros casos autóctones por ARANTES ${ }^{4}$, no município de Santos; e, a partir dai, vários estudos foram realizados, sendo descobertos outros casos autóctones em mais 22 municípios.

Como muitos dos familiares de pacientes esquistossomóticos, por nós assistidos, eram procedentes das mesmas regiões endêmicas e, portanto, prováveis por-

- Trabalho apresentado na disciplina Administração Aplicada à Enfermagem I da EEUSP.

** Aluna do Curso de Graduação em Enfermagem e Obstetricia da EEUSP. 
tadores da doença, iniciamos uma investigação no intuito de conhecer qual a assistência prestada a esses familiares.

Vários autores ${ }^{5,8,9,11}$ consideram a esquistossomose como uma das enfermidades mais significativas no atraso do desenvolvimento dos países tropicais, pois transforma muitos membros da sociedade em indivíduos incapacitados para o trabalho.

Além de CODA et alii. ${ }^{5}$ e KOROLKOVAS ${ }^{11}$, outros autores ${ }^{7,10,15,16,17}$, estudando a etiopatogenia, incidência e tratamento da esquistossomose, colocam as seguintes etapas que devem ser consideradas para a resolução do problema:

1) portador - tratamento específico;

2) hospedeiro - controle da população de planorbídeos, principalmente onde houver foco atual ou potencial, sendo para isto utilizados os moluscocidas;

3) meio - medidas de saneamento básico: drenagem e aterro de charcos e lagoas; construção de redes de esgotos; instalação de água encanada; utilização de fossas secas ou sépticas;

4) comunidade - orientação sanitária.

A partir dai, e visando a $1 .^{\mathrm{a}}$ e $4 .^{\mathrm{a}}$ etapas, consideramos imprescindivel a elaboração de um plano assistencial no sentido de detectar a doença, educar e tratar familiares de pacientes esquistossomóticos em fase menos avançadas e menos problemáticas da doença, quando o tratamento é bastante simples e bem menos oneroso, consistindo no uso de drogas.

AGOSTINE ${ }^{1}$, AMATO NETO ${ }^{2}$, AMATO NETO et alii ${ }^{3}$, KOROLKOVAS ${ }^{11}$ e um grupo de trabalho sobre terapêutica da esquistossomose ${ }^{6}$ evidenciam, em seus estudos, resultados obtidos no tratamento da esquistossomose com drogas como o HYCANTHONE e o ETRENOL. No I Encontro Nacional sobre Esquistossomose ${ }^{7}$, há citações quanto aos estudos realizados com essas mesmas drogas. Outro medicamento comumente utilizado é o MANSIL.

$\mathrm{Na}$ tentativa de obtermos recursos onde pudessem ser realizados os exames laboratoriais para diagnóstico da esquistossomose, recorremos ao Serviço de Relações Públicas do Hospital das Clínicas, quando nos foram indicados os seguintes serviços: Instituto Adolfo Lutz (IAL), Superintendência de Controle de Endemias (SUCEN) e os Centros de Saúde.

Recorremos, primeiramente, à Seção de Enteroparasitose do IAL, onde conseguimos que fossem realizados 15 (quinze) exames de fezes de familiares de pacientes esquistossomóticos, por semana.

Além disso, por intermédio da enfermeira chefe da Unidade, tomamos conhecimento de que no Instituto de Medicina Tropical (IMT) estava sendo realizada uma pesquisa relacionada a um medicamento usado no tratamento da esquistossomose. Esse Instituto prontificou-se a efetuar o tratamento de 3 (três) indivíduos por semana.

Numa tentativa de dar cobertura às etapas 2 e 3 , entramos em contato com a SUCEN, ficando estabelecido que, posteriormente, deveria ser criado um sistema de informação entre a SUCEN e a $3 .^{a}$ Clínica Cirúrgica, a fim de que aquela 
entidade, obedecendo à Política Sanitária aprovada na sessão de 15/06/1977 do Conselho Técnico de Coordenação das Atividades de Combate à Esquistossomose, tomasse conhecimento dos locais onde estivessem residindo os indivíduos portadores da doença.

Se necessário, seria iniciado um inquérito epidemiológico no intuito de localizar novos focos ativos da moléstia em São Paulo. Seriam, também, tomadas medidas cabíveis a curto prazo, ou seja, inativação desses focos mediante a aplicação de moluscocidas e a manutenção desses focos sob controle. Isso se torna necessário, enquanto não for possivel a eliminação definitiva dos focos através das obras de saneamento básico.

Até o presente momento foram atendidos, através do plano assistencial proposto, 129 (cento e vinte e nove) familiares; destes, $20,1 \%$ apresentaram esquistossomose, $17,8 \%$ outras parasitoses, $13,1 \%$ foram totalmente negativos e $49,0 \%$, sem resultados. Devemos, porém, ressaltar que estes dados não são significativos por ser o tempo de aplicação ainda pequeno (novembro de 1977 a janeiro de 1978), e ser elevado o número de exames sem resultados quando da coleta de dados.

Tendo em vista a grande incidência de outras parasitoses que não a esquistossomose, viu-se necessidade de se providenciar tratamento adequado para elas, o que, temporariamente, está sendo feito no IMT. Terminado o prazo estabelecido por este, os indivíduos serão encaminhados aos Centros de Saúde dos bairros, visto ser desnecessário e oneroso o tratamento dessas parasitoses no hospital.

Para dar cobertura ao plano assistencial, na parte referente à educação e ao tratamento dos familiares de pacientes esquistossomóticos, elaboramos o roteiro de orientação (Anexo 1) e o plano de atendimento de pacientes e familiares (Anexo 2$)$.

0 roteiro para orientação de pacientes e familiares de pacientes esquistossomóticos foi elaborado com a finalidade de facilitar o trabalho das enfermeiras responsáveis por esta tarefa. $O$ plano de atendimento a esses familiares especifica cada passo que deve ser seguido para o andamento do trabalho de maneira sistematizada. Foi incluido neste plano o item "maneira correta de colher as fezes", tendo em vista que a maioria das pessoas o faz incorretamente, dando margem ao aparecimento de resultados falsamente negativos.

A implantação desses instrumentos foi realizada por nós durante o estágio e a continuação está sendo feita pelas enfermeiras da Unidade.

Com a publicação deste trabalho esperamos estar contribuindo para alertar a equipe de saúde, em especial a enfermeira, sobre o papel relevante que ela pode ter no combate à esquistossomose e a outras endemias, dentro dos hospitais.

RAMOS, M. A. de A.; PONTIES, M. A.; BAPTISTA, M. A.; PATRIClO, S. R.; HALTER, Z. Contribution of the nurse in the fight against schistosomosis in hospitals. Rev. Esc. Enf. USP, São Paulo, 13(2): 189-196, 1979.

The authors, who are undergraduate nursing students, describe one of their activities in their field experience in Nursing Administration. They give the description of a plan they made for early detection of schistosomosis in family members of patients with the disease; implementation of the plan; and orientation and treatment of the ones with positive laboratory results. 


\section{REFERENCIAS BIBLIOGRAFICAS}

1. AgOStine, A. R. - Tratamento da esquistossomose com Hycanthone. A Folha Médica, Rio de Janeiro, 65(2): 313, ago. 1972.

2. AMATO NETO, V. - Esquistossomiase mansoni no Estado de São Paulo. Rev. paul. Med., São Paulo 80(1): 41.2, 1972.

3. —— et alii - Esquistossomíase mansônica. In Tratamento das doenças parasitárias. São Paulo, Gremed, 1976 . p. 53-60.

4. ARANTES, A. - Sobre dois casos de Schistosomose autóctone em Santos. An. paul. Med. Cirurg., São Paulo, 14(9): 95-6, 1923

5. CODA, D. et alii - Contribuição para o estudo e profilaxia da esquistossomose mansônica no Estado de São Paulo. Rev. Inst. Adolfo Lutz, São Paulo, 19 (n." único): 25-68, 1959.

6. CONCLUSOES e recomendações do grupo de trabalho sobre terapêutica da esquistossomose. Bol. Epidem., Rio de Janeiro, 3(5): 33-5, 1971.

7. ENCONTRO NACIONAL SOBRE ESQUISTOSSOMOSE, 1.० São Paulo, 4 a 6 junho 1973.

8. ESQUISTOSSOMOSIS: Enfermedad parasitaria que invalida a millones. Gaceta, Washington, 3(3): $7 \cdot 16$, jul./set. 1971 .

9. ESQUiSTOSSOMfase: 20 milhōes de casos (O Nilo). Saúde do Mundo, Washington, 13(3): 8, maio-jun. 1962.

10. KAWAMOTO, E. E. - Hipertensão portal decorrente da esquistossomose: aspectos de enfermagem. Rev. Bras. Enf., Brasília, 31: 215-21, 1978.

11. KOROLKOVAS, A. - Bioquimica e quimioterapia da esquistossomose. Rev. Fac. Farm. Bioquím. da USP, São Paulo, 5(1): 5.48, jan./jun. 1967.

12. MOLINA, R. R. - Doenças produzidas por Trematódios. In: HARRISON, T. R. Medicina Interna. 2. ed. Rio de Janeiro, Guanabara Koogan, 1956. T. 2, p. 1206-12.

13. OKUMURA, M. - Hipertensão portal. In: ZERBINI, E. J. Clínica cirúrgica Alipio Correa Neto. 3. ed. São Paulo, Sarvier, 1974. v. 5. p. 324-58.

14. PESSOA, S. B. - Trematódios parasitas do sistema sanguíneo. Schistosoma mansoni. In:

- Parasitologia médica. 6. ed. Rio de Janeiro, Guanabara Koogan, 1963. p. 349-95.

15. PIZA, J. T. - A esquistossomose em São Paulo: o que nos ensina a experiência de 6 anos de tra. balhos no campo. Arch. Hig., São Paulo, 30/1 (103/10): 6-24, 1965-66.

16. PIZA, . T. \& Ramos, A. S. - Os focos autóctones da esquistossomose no Estado de São Paulo. Arch. Hig., São Paulo, 25(86): 261-71, dez. 1960.

17. PIZA, J. T. et alii - A esquistossomose no Estado de São Paulo. Novas diretrizes e atividades. Arch. Hig., São Paulo, 34(119-20): 5-24, mar./jun. 1969.

\section{BIBLIOGRAFIA CONSULTADA}

1. BASTOS, C. O. - Primeiros casos presumivelmente autóctones de esquistossomose na cidade de São Paulo, 53(2): 133-4, 1958

2. COUTINHO, E. - Esquistossomíase intestinal. In: ___ Tratado de clinica das doenças infectuosas e parasitárias. Rio de Janeiro, Guanabara Koogan, 1951. p. 487-94.

3. CUNHA, A. S. - Esquistossomose mansoni. Săo Paulo, Sarvier, 1970.

4. MORAES, R. G. et alii - Familia Schistosomidae: Gênero Schistosoma. Morfologia e ciclo evolutivo do Schistosoma mansoni. In: _- Parasitologia médica. Rio de Janeiro, Atheneu, 1971. p. 174-94.

5. PRATA, A. - Esquistossomose mansoni. In: VERONESI, R. Doenças infecciosas e parasitárias. 5. ed. Rio de Janeiro, Guanabara Koogan, 1972 . p. 870-92.

6. RAMOS, A. S. et alii - Focos ativos de esquistossomose mansoni no Vale do Ribeira. Rev. Saúde Pública, Sāo Paulo, 3(1): 39-63, jun. 1969.

7. RODRIGUES, D. C. \& FERREIRA, C. G. - Foco ativo de esquistossomiase mansoni no município de São Paulo. O Hospital, São Paulo, 70(6): 171-7, 267-76, (separata), dez. 1966. 


\section{ANEXO 1}

\section{ROTEIRO PARA ORIENTAÇÃO DE PACIENTES E FAMILIARES DE PACIENTES ESQUISTOSSOMÓTICOS}

DEFINIÇ $\tilde{A} O$ : A esquistossomose é uma doença crônica endêmica produzida no homem por infecção pelo verme do gênero Schistosoma. Instala-se, geralmente, no cólon, no fígado, na bexiga, no baço, no reto, nos pulmões, na genitália, no mesentério e no peritônio.

No Brasil, a espécie causadora da esquistossomose é a Schistosoma mansoni. EPIDEMIOLOGIA: No indivíduo portador da doença, a fêmea do Schistosoma mansoni põe seus ovos nas veias da submucosa intestinal, que levam as paredes dos vasos sangüíneos, atingindo a luz intestinal. Com a passagem do bolo fecal, os ovos são arrastados e eliminados, o que pode levar à contaminação das águas em locais onde não exista nenhum recurso de saneamento com fossas e latrinas. Esses ovos, em contacto com a água, eliminam larvas denominadas miracídios que, encontrando a espécie de caramujo adequada (hospedeiro intermediário), nela penetram transformando-se em milhares de cercárias, que são liberadas novamente na água, indo penetrar nos indivíduos, em contacto com ela, através da pele ou da mucosa.

A esquistossomose é uma doença de alta incidência em jovens a partir dos quatro anos de idade; a doença que se manifesta no adulto é, geralmente, conseqüência de manifestação adquirida quando jovem.

NOTA: roedores e marsupiais fazem parte, também, do ciclo biológico da esquistossomose como possiveis portadores da doença.

\section{TIPOS:}

1) Intestinal: diarréia com ou sem expulsão de fezes muco-sanguinolentas; dor abdominal e no hipocôndrio direito; dor à palpação cecal; fígado e baço não palpáveis.

2) Hepato-intestinal: sintomas intestinais semelhantes ao tipo 1; maior porcentagem de casos com diarréia e epigastralgia; figado aumentado de volume; baço não palpável.

3) Hepato-esplenomegálico: fase de cirrose compensada. Além da sintomatologia intestinal, há aumento do volume do fígado com tendência à hepatomegalia; baço palpável sem tendência à esplenomegalia; estado-geral deficiente; anemia moderada.

4) Hepato-esplenomegálico fase de cirrose descompensada. Grandes esplenomegalias, em geral, baço palpável até ou além da cicatriz umbilical. Fígado pequeno e contraído ou hepatomegalia. Em geral, ascite, hematêmese ou circulação colateral, perturbações freqüentes do aparelho respiratório, emagrecimento e desnutrição acentuada.

SINTOMAS GERAIS: Diarréia ou prisão de ventre, febre, mal-estar, fraqueza, falta de apetite, prostração, náuseas. 
DIAGNÓSTICO: A maneira mais comumente utilizada para o diagnóstico é o exame parasitológico das fezes.

TRATAMENTO: 0 tratamento e a cura do esquistossomótico é feito através de medicamentos específicos. $\mathbf{O}$ prognóstico é bom desde que o paciente procure aten. dimento médico logo no início das manifestações sintomáticas da doença, ou seja, antes que os órgãos vitais sejam comprometidos.

\section{PROFILAXIA:}

- extermínio dos focos ativos da moléstia pelo uso de moluscocidas (ex. BAY. LUCID, FRESCON);

- educação sanitária: educar os indivíduos, mostrando-lhes os perigos de se banharem em águas altamente infestadas;

- tratamento da água utilizada para fins domésticos;

- orientação quanto à construção e uso adequado de fossas sanitárias;

- drenagens e aterros de lagoas, valas e córregos;

- construção de redes de esgotos;

— diagnósticos e tratamento dos doentes. 


\section{ANEXO 2 \\ PLANO DE ATENDIMENTO A FAMILIARES DE PACIENTES ESQUISTOSSOMÓTICOS}

I) Seleção e orientação dos familiares de esquistossomóticos.

- Entrevistar pacientes esquistossomóticos, verificando quantos dos seus familiares, oriundos da mesma região, estão atualmente residindo em São Paulo, convocando-os comparecerem ao hospital nos horários de visita (dois familiares por dia).

- Salientar nesta entrevista, a importância da realiazção de um exame de fezes em todas as pessoas que tiverem contato com regiões onde a esquistossomose é endêmica, ou que apresentam sintomatologia característica da doença.

- Orientar estes familiares a colherem fezes para o exame parasitológico de maneira adequada, fornecendo-lhes o material necessário (latas e espátulas).

- Orientá-los para que retornem ao hospital às segundas-feiras com o material colhido e identificado.

II) Maneira correta de se colher as fezes para o exame.

- Colher de vários pontos da massa fecal em casos de fezes ressecadas, ou então, em casos de fezes pastosas, homogeinizá-las para depois colher uma porção.

- Não guardar em geladeira, mas conservar o material em lugar fresco.

III) Encaminhamento do material ao Instituto Adolfo Lutz

- Providenciar requisição do exame para serem enviados, juntamente com o material, ao Instituto Adolfo Lutz. Esta requisição deverá ser aquela normalmente utilizada no Hospital das Clínicas, devendo ser acrescentados os seguintes itens:
a) Nome
b) Registro (para controle do hospital e Instituto)
c) Idade
c) Cor
e) Naturalidade
f) Residência anterior
g) Residência atual
h) Tempo de moradia em São Paulo
i) Finalidade do exame (diagnóstico ou tratamento)
j) Assinatura de um médico (se possível)

As requisições, juntamente com o material, deverão ser encaminhados ao Instituto Adolfo Lutz, por um funcionário da unidade, às segundas-feiras, no período da manhã, se possivel, ou à tarde entre 14 e 14:30 horas. 
NOTA: - Deverão ser enviados, no máximo, 15 (quinze) requisições por semana.

Os resultados deverão ser recolhidos por um funcionário após 8 (oito) dias, ou seja, na segunda-feira seguinte.

Caso algum paciente ou familiar encontrar na região de sua residência atual, caramujos em lagoas, poderá trazê-los ao hospital para serem enviados ao Instituto Adolfo Lutz.

\section{IV) Controle}

- O controle do material enviado, será feito pela clínica através de um livro contendo os itens:

Data

Registro

Nome

Idade

Naturalidade

Residência Anterior

Residência Atual

Tempo de moradia em São Paulo

Resultado do exame

Encaminhamento ao IMT

Este livro deverá ser guardado numa das gavetas do posto de enfermagem e o material, numa caixa devidamente identificada, que ficará sobre o balcão do posto.

OBSERVAÇÃO: O registro de controle utilizado pela clínica será conservado pelo Instituto.

Endereço do Instituto Adolfo Lutz

Avenida Dr. Arnaldo, n. ${ }^{\circ} 355$

Prédio da Biologia Médica - Seção de Enteroparasitose - $4 .^{\circ}$ andar

Fone $853-0111$

V) Encaminhamento dos familiares de pacientes esquistossomóticos ao Instituto de Medicina Tropical

- Os familiares, cujos resultados dos exames realizados no Instituto Adolf Lutz forem positivos para esquistossomose, deverão colher nova amostra de fezes e dirigir-se ao ambulatório do IMT, às quartas-feiras, no período da manhã, onde será feito o tratamento e seguimento adequados. Em casos de exames positivos para outras parasitoses, deverão ser encaminhados às segundas-feiras, no periodo da tarde para o mesmo local, anteriormente citado.

NOTA: Deverão ser enviados, no máximo 3 (três) pessoas por semana.

Endereço do Instituto de Medicina Tropical

Avenida Dr. Enéas de Carvalho Aguiar, n..$^{\circ} 470$

(ao lado da Faculdade de Medicina da Universidade de São Paulo) 